\title{
Mapping Callosal Morphology in Early- and Late-Onset Elderly Depression: An Index of Distinct Changes in Cortical Connectivity
}

\author{
Martina Ballmaier ${ }^{1,2,3}$, Anand Kumar ${ }^{4}$, Virginia Elderkin-Thompson ${ }^{4}$, Katherine L Narr ${ }^{2}$, Eileen Luders ${ }^{2}$, \\ Paul M Thompson ${ }^{2}$, Cornelius Hojatkashani ${ }^{2}$, Daniel Pham ${ }^{4}$, Andreas Heinz' and Arthur W Toga*,2 \\ 'Department of Psychiatry and Psychotherapy, Charité University Medicine, Campus Mitte, Berlin, Germany; 'Laboratory of Neuro Imaging, \\ Department of Neurology, University of California at Los Angeles, Los Angeles, CA, USA; ${ }^{3}$ Department of Biomedical Sciences \& Biotechnologies, \\ Brescia University Medical School, Brescia, Italy; ${ }^{4}$ Department of Psychiatry and Biobehavior, Semel Institute for Neuroscience and Human \\ Behavior, University of California at Los Angeles, Los Angeles, CA, USA
}

\begin{abstract}
There is some evidence of corpus callosum abnormalities in elderly depression, but it is not known whether these deficits are regionspecific or differ based on age at onset of depression. Twenty-four patients with early-onset depression (mean age $=68.00, S D \pm 5.83$ ), 22 patients with late-onset depression (mean age $=74.50, \mathrm{SD} \pm 8.09$ ) and 34 elderly control subjects (mean age $=72.38 ; \mathrm{SD} \pm 6.93$ ) were studied. Using 3D MRI data, novel mesh-based geometrical modeling methods were applied to compare the midsagittal thickness of the corpus callosum at high spatial resolution between groups. Neuropsychological correlates of midsagittal callosal area differences were additionally investigated in a subsample of subjects. Depressed patients exhibited significant callosal thinning in the genu and splenium compared to controls. Significant callosal thinning was restricted to the genu in early-onset patients, but patients with late-onset depression exhibited significant callosal thinning in both the genu and splenium relative to controls. The splenium of the corpus callosum was also significantly thinner in subjects with late- vs early-onset depression. Genu and splenium midsagittal areas significantly correlated with memory and attention functioning among late-onset depressed patients, but not early-onset depressed patients or controls. Circumscribed structural alterations in callosal morphology may distinguish late- from early-onset depression in the elderly. These findings suggest distinct abnormalities of cortical connectivity in late- and early-onset elderly depression with possible influence on the course of illness. Patients with a late onset of depression may be at higher risk of illness progression and eventually dementia conversion than earlyonset depression, with potentially important implications for research and therapy.

Neuropsychopharmacology (2008) 33, I528-1536; doi:I0. I038/sj.npp. I 301538; published online 22 August 2007
\end{abstract}

Keywords: corpus callosum; mapping; depression; elderly; late-onset; early-onset

\section{INTRODUCTION}

Studies of elderly depressed patients have repeatedly suggested a potential involvement of the prefrontal cortex and temporal lobe structures, such as the hippocampus, in the disorder (for review see Alexopoulos et al, 2005; Steffens et al, 2006). In a subset of elderly depressed patients with major depression, the first episode occurs late in life (Alexopoulos et al, 1988). This subgroup, frequently referred to as having late-onset depression, exhibits certain unique clinical, biological, and neuroimaging characteristics (Burvill et al, 1989; Heun et al, 2000; Krishnan et al, 1995,

* Correspondence: Professor AW Toga, Laboratory of Neuro Imaging Department of Neurology, University of California at Los Angeles, 635 Charles Young Drive, Suite 225, Los Angeles, CA 90095, USA, Tel: + 3102062101 , Fax: + 310206 5518, E-mail: toga@loni.ucla.edu Received 27 April 2007; revised I 6 July 2007; accepted I6 July 2007
1997; Schweitzer et al, 2002), implying that late-onset depression may represent a distinct subtype of depression in the elderly. Along with observations of greater cognitive deficits (Salloway et al, 1996) and an increased risk of dementia conversion (Geda et al, 2006; Schweitzer et al, 2002), there is some evidence that patients with late-onset depression may have more pronounced atrophy in cortical and subcortical regions implicated in the pathophysiology of elderly depression (Almeida et al, 2002; Hickie et al, 2005; Steffens et al, 2000). Using traditional volumetric region of interest analyses and computational cortical mapping methods, we previously found complex structural changes in frontal and temporo-parietal brain regions, which may point to differential patterns of atrophic or neurodegenerative processes that may be influenced by age at illness onset (Ballmaier et al, 2004a, b, c).

The corpus callosum is the largest interhemispheric white matter commissure and is known to modulate interhemispheric 
communication and cognitive processes (Gazzaniga, 2000; Sanchez et al, 1998). Subregions of the corpus callosum topographically map various cortical areas that have been involved in elderly depression. Therefore, the corpus callosum appears to be an attractive candidate for exploring the neuroanatomical changes underlying the pathophysiology of depressed elders. Here we aimed to identify regional alterations of callosal morphology in elderly depression and to shed light on the hypothesis that early- and late-onset depression may present distinct structural characteristics.

Structural neuroimaging research on regional differences in callosal size are commonly based on the segmentation criteria suggested by Witelson (1989). These subdivision criteria have recently generated some controversy with respect to the assumed topography of callosal fibers (Hofer and Frahm, 2006). Indeed, this method arbitrarily divides the midsagittal corpus callosum into several regions according to maximal length and thus could be biased by local variability in callosal shape. To circumvent the risk of defining the callosal sections with implicit assumptions regarding sectors with consistent fiber distribution and to increase spatial resolution of callosal measurements, we characterized callosal abnormalities by applying anatomical mesh-based geometrical modeling methods, which compute 100 pointwise indicators of callosal thickness across the whole corpus callosum at midline (Luders et al, 2006a, b; Narr et al, 2000, 2002; Vidal et al, 2006). Importantly, these mapping methods detect and visualize the spatial patterns of callosal abnormalities using color-coded statistical maps, revealing any highly localized group differences in callosal thickness.

On the basis of our previous findings, we predicted callosal abnormalities in the genu and the splenium, both of which interconnect cortical regions previously implicated in elderly depression. Owing to the paucity of available data, we did not predict which regions of the corpus callosum would be affected based on age at illness onset. Finally, we examined the relationship between callosal areas and neuropsychological measures of memory and attention in a subsample of subjects, given that these measures may be affected by interhemispheric communication as well as hemispheric competence.

\section{MATERIALS AND METHODS}

\section{Subjects}

Subjects were recruited through local newspapers and radio advertisements and through referrals from the geriatric psychiatry ambulatory care programs at the University of California, Los Angeles (UCLA) Medical Center. Tables 1 and 2 show the demographic characteristics of the sample. Forty-six elderly depressed patients 60 years or older with major depression who fulfilled DSM-IV criteria for major depression (and scored 15 or more on the Hamilton Rating Scale for Depression; Hamilton, 1967) were included in the study. The control group consisted of thirty-four similaraged older people with no past history of depression or current depression. The cohort with depression was subdivided into those with early- and late-onset depression, using onset of the first major depressive episode after age 60 as cutoff (24 subjects with early-onset depression, 22 subjects with late-onset depression). Information on previous episodes and the age of onset was provided by patients and caregivers. Exclusion criteria for both patients and controls were (1) neurologic illness, including history or evidence of stroke, transient ischemic attack and clinical evidence of dementia or suspected dementia; (2) serious or unstable physical illness (eg insulin-dependent diabetes mellitus, uncontrolled heart failure, cancer); (3) illness or medication precluding cognitive testing; (4) alcohol abuse or dependence, and (5) metal in the body precluding magnetic resonance imaging (MRI). In addition, none of the patients had another major psychiatric illness or histories of long-term antidepressant treatment in the past. All patients were free of psychotropic medications for at least 2 weeks

Table I Demographic and Clinical Data of Participants with and without Depression with Overall Group Effect

\begin{tabular}{|c|c|c|c|c|c|}
\hline & $\begin{array}{c}\text { Comparison } \\
\text { subjects } N=34\end{array}$ & $\begin{array}{c}\text { Subjects with } \\
\text { depression } N=46\end{array}$ & \multicolumn{3}{|c|}{ Analysis } \\
\hline Mini-mental state examination score & $29.48( \pm 0.79)$ & $28.68( \pm 1.45)$ & 2.86 & 75 & 0.01 \\
\hline Gender (female/male) & $19 / 15$ & $34 / 12$ & $\chi^{2}=2.84$ & । & 0.09 \\
\hline CVRF score & $11.19( \pm 6.68)$ & $11.00( \pm 5.36)$ & 0.14 & 73 & 0.89 \\
\hline Total brain volume & $1286.93( \pm \mid 38.72)$ & $1295.68( \pm \mid 29.61)$ & -0.29 & 78 & 0.77 \\
\hline Splenium & $203.975( \pm 35.22)$ & $183.26( \pm 35.90)$ & $F=8.48$ & 1,75 & 0.005 \\
\hline Isthmus & $65.365( \pm 10.70)$ & $60.980( \pm 13.95)$ & $F=2.85$ & 1,75 & 0.096 \\
\hline Posterior midbody & $77.345( \pm 11.60)$ & $74.920( \pm 11.79)$ & $F=0.42$ & 1,75 & 0.519 \\
\hline
\end{tabular}


Table 2 Demographic and Clinical Data of Participants with and without Depression Dichotomized for Age of Depression Onset

\begin{tabular}{|c|c|c|c|c|c|c|c|c|c|}
\hline & \multirow{2}{*}{$\begin{array}{c}\text { Comparison } \\
\text { subjects } N=34\end{array}$} & \multicolumn{2}{|c|}{ Subjects with depression } & \multicolumn{2}{|c|}{ Control vs early onset } & \multicolumn{2}{|c|}{ Control vs late onset } & \multicolumn{2}{|c|}{ Early vs late onset } \\
\hline & & Early-onset $N=24$ & Late-onset $N=22$ & $\boldsymbol{F}$ & $\mathbf{P}$ & $\boldsymbol{F}$ & $\mathbf{P}$ & $\boldsymbol{F}$ & $\mathbf{P}$ \\
\hline \multirow[t]{2}{*}{ Age } & 72.38 & 68.00 & 74.50 & $F(1,56)$ & 0.042 & $F(1,54)$ & 0.301 & $F(I, 44)$ & 0.009 \\
\hline & $( \pm 6.93)$ & $( \pm 5.83)$ & $( \pm 8.09)$ & 6.38 & & 1.09 & & 9.87 & \\
\hline \multirow[t]{2}{*}{ Mini-Mental State Examination score } & 29.48 & 28.72 & 28.64 & $F(1,53)$ & 0.024 & $F(1,53)$ & 0.004 & $F(1,42)$ & 0.839 \\
\hline & $( \pm 0.79)$ & $( \pm 1.61)$ & $( \pm 1.33)$ & 5.38 & & 5.53 & & 0.04 & \\
\hline \multirow[t]{2}{*}{ Gender (female/male) } & $19 / 15$ & $20 / 4$ & $14 / 8$ & $\chi^{2}$ & 0.056 & $\chi^{2}$ & 0.766 & $\chi^{2}$ & 0.237 \\
\hline & & & & 3.647 & & 0.089 & & 1.401 & \\
\hline \multirow[t]{2}{*}{ Age of onset, years } & - & 33.25 & 71.27 & - & - & - & - & - & - \\
\hline & & $( \pm 16.05)$ & $( \pm 7.23)$ & & & & & & \\
\hline \multirow[t]{2}{*}{ Previous episodes of depression } & - & 4.80 & 0.50 & - & - & - & - & - & - \\
\hline & & $( \pm 4.13)$ & $( \pm 0.90)$ & & & & & & \\
\hline \multirow[t]{2}{*}{ Hamilton depression score } & - & 17.33 & 18.13 & - & - & - & - & $F(1,44)$ & 0.389 \\
\hline & & $( \pm 2.63)$ & $( \pm 3.77)$ & & & & & 0.76 & \\
\hline \multirow[t]{2}{*}{ Total brain volume } & 1286.93 & 1273.98 & 1318.28 & $F(1,56)$ & 0.746 & $F(1,54)$ & 0.388 & $F(I, 44)$ & 0.262 \\
\hline & $( \pm \mid 38.72)$ & $( \pm 137.13)$ & $( \pm|| 9.9 \mid)$ & 0.11 & & 0.76 & & 1.29 & \\
\hline \multirow[t]{2}{*}{ CVRF score } & 11.19 & 9.36 & 12.64 & $F(1,5 \mid)$ & 0.271 & $F(|, 5|)$ & 0.414 & $F(I, 42)$ & 0.041 \\
\hline & $( \pm 6.68)$ & $( \pm 4.57)$ & $( \pm 5.69)$ & 1.24 & & 0.68 & & 4.42 & \\
\hline \multirow[t]{2}{*}{ Splenium } & 203.975 & 199.16 & |65.9| & $F(1,53)$ & 1.00 & $F(I, 5 I)$ & $<0.001$ & $F(|, 4|)$ & 0.015 \\
\hline & $(35.22)$ & $( \pm 28.36)$ & $( \pm 35.74)$ & 0.16 & & 15.06 & & 8.73 & \\
\hline \multirow[t]{2}{*}{ Isthmus } & 65.365 & 64.845 & 56.765 & $F(1,53)$ & 1.00 & $F(|, 5|)$ & 0.065 & $F(\mid, 4 I)$ & 1.00 \\
\hline & $( \pm \mid 0.7)$ & $( \pm 10.26)$ & $( \pm 16.05)$ & 0.01 & & 5.60 & & 0.91 & \\
\hline \multirow[t]{2}{*}{ Posterior midbody } & 77.345 & 74.145 & 75.780 & $F(1,53)$ & 1.00 & $F(I, 5 I)$ & 1.00 & $F(\mid, 4 I)$ & 0.985 \\
\hline & $( \pm \mid 1.60)$ & $( \pm 9.7)$ & $( \pm 13.92)$ & 0.06 & & 0.50 & & 0.98 & \\
\hline \multirow[t]{2}{*}{ Anterior midbody } & 84.145 & 81.320 & 81.065 & $F(1,53)$ & 1.00 & $F(|, 5|)$ & 0.948 & $F(|, 4|)$ & 1.00 \\
\hline & $( \pm 12.68)$ & $( \pm 10.28)$ & $( \pm \mid 4.84)$ & 0.27 & & 1.03 & & 0.49 & \\
\hline \multirow[t]{2}{*}{ Anterior third } & 312.895 & 260.185 & 257.475 & $F(1,53)$ & 0.015 & $F(I, 5 I)$ & 0.003 & $F(\mid, 4 I)$ & 0.934 \\
\hline & $( \pm 54.05)$ & $( \pm 42.42)$ & $( \pm 62.53)$ & 8.65 & & 12.25 & & 1.05 & \\
\hline
\end{tabular}

CVRF, cardiovascular risk factor.

All area measurements, expressed in $\mathrm{mm}^{2}$, are shown after correcting for age, gender and total brain volume. Total brain volumes are shown in $\mathrm{cm}^{3}$. 
before imaging. A neuropsychiatric examination and the structured clinical diagnostic interview for normal subjects were administered to all control subjects to rule out current or past psychopathology. All subjects underwent MiniMental State Examination (Folstein et al, 1975). A subset of the larger study group completed a small neuropsychological test battery, including two tasks from the California Verbal Learning Test (CVLT) (Delis et al, 1987) to capture learning (CVLT trials 1-5) and recall (20 min CVLT delayed recall) and one task from the Stroop paradigm to assess sustained attention with a motor response (Stroop Part 1) (Stroop, 1935).

The study was performed in accordance with the policies of the UCLA Human Subjects Protection Committees, and all subjects gave written consent to participate. We have previously published cortical abnormalities in a smaller sample than reported here (Ballmaier et al, 2004a, b, c).

\section{Magnetic Resonance Imaging}

All subjects were studied with MRI performed on a 1.5-T Signa magnet (GE Medical Systems, Milwaukee) using a coronal $\mathrm{T}_{1}$-weighted spoiled gradient/recall acquisition in the steady state (spoiled GRASS) with the following parameters: repetition time $=20 \mathrm{~ms}$; echo time $=6 \mathrm{~ms}$; flip angle $=45$ degrees; $1.4 \mathrm{~mm}$ slice thickness without gaps; filed of view $=22 \mathrm{~cm}$; number of excitations $=1.5$; matrix size $=256 \times 192 \mathrm{~mm}$; in-plane resolution $=0.86 \times 0.86 \mathrm{~mm}$.

\section{Image Preprocessing}

Image processing, callosal thickness, and callosal area measurements were performed as detailed previously (Luders et al, 2006a, b; Narr et al, 2000, 2002; Vidal et al, 2006). Each brain volume was corrected for radiofrequency field inhomogeneities (Sled and Pike, 1998) and placed into the standard coordinate system of the ICBM-305 average brain volume using a three-translation and three-rotation rigid-body transformation (Woods et al, 1998). This procedure corrects for differences in head alignment between subjects to assure that region of interest measurements are not influenced by different brain orientation. The corpus callosum was traced in midsagittal sections with the upper (top) and lower (bottom) callosal boundaries being delineated separately. To obtain the most accurate possible measure of midsagittal callosal area, the three most medial brain slices were included ( $1 \mathrm{~mm}$ slice thickness). For interrater reliability, two independent investigators contoured the corpus callosum in six different randomly selected brains, achieving intraclass correlation coefficients of $r=0.97$. The callosal contours were traced by one rater blind to diagnosis.

\section{Callosal Thickness and Area Measurements}

Callosal thickness measurements were performed after correcting brains for head position and tilts but preserving original brain size. Callosal top and bottom sections were redigitized, converting them into 100 equidistant points along the midsagittal callosal curve per section. A medial line was then calculated as the average curve between the superior and inferior callosal boundaries in each subject, followed by computing the pointwise distances from this medial line to the callosal top and bottom traces (Figure 1a). Subsequently, individual pointwise distance values, indexing callosal thickness, were compared across subjects at spatially homologous callosal surface points.

To obtain measures of corpus callosum morphology consistent with regional measurements more typically reported in the literature, the callosal renderings from each brain volume were reoriented to maximize callosal length and divided into five vertical partitions representing (1) the splenium, (2) isthmus, (3) the posterior midbody (4) the anterior midbody and, (5) the anterior third as visualized in Figure 1b (Witelson, 1989). Areas measures were computed in $\mathrm{mm}^{2}$ for each callosal segment, as described previously (Narr et al, 2002; Vidal et al, 2006).

\section{Statistical Analyses}

Statistical analyses examined whether differences in callosal thickness and area measures were present in patients compared to healthy comparison subjects, and in patients based on age of illness onset. That is, using either midsagittal callosal area or regional thickness measures as dependent variables, we employed the general linear model to establish the presence of overall diagnostic group effects (controls $v s$ all depressed patients), covarying for age, sex, and total brain volume. Significant overall group effects were followed up by examining differences between earlyonset depression and controls, late-onset depression and controls, as well as between the two disease groups (early$v s$ late-onset depression). Age, gender, and total brain volume were again included as covariates. Post hoc Bonferroni corrections were used to control for potential

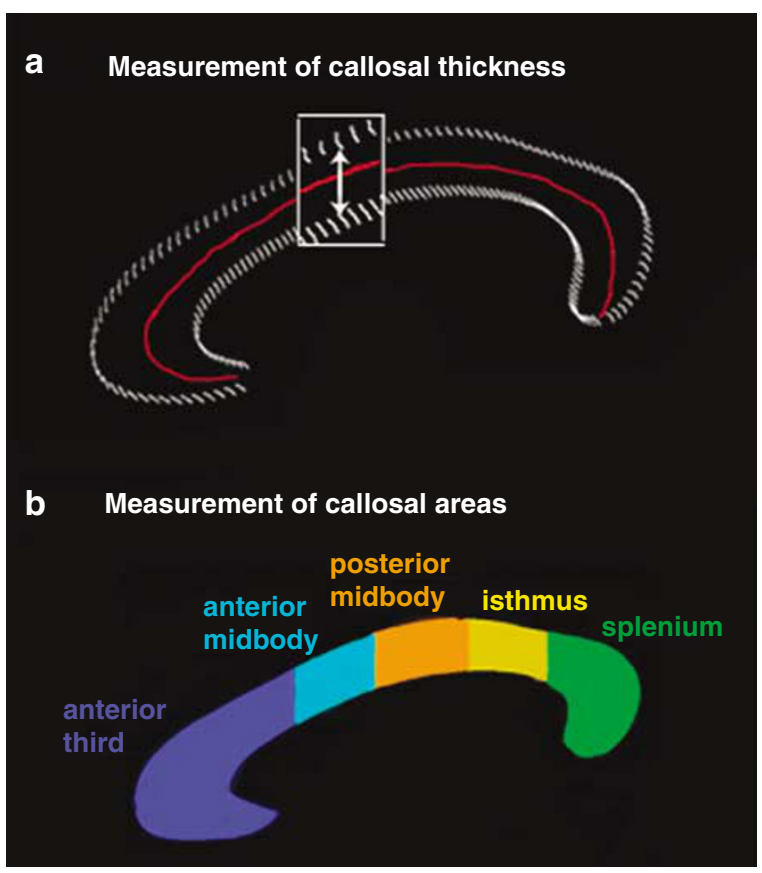

Figure I (a) The pointwise distances between the medial curve (in red) and the callosal top and bottom segments are superimposed as colorcoded values on each subject's callosal surface model. (b) Subdivision of the corpus callosum in five areas according to the Witelson scheme. 
inflated Type I error for analyses of midsagittal callosal areas. Since comparisons of callosal thickness were made at one hundred equidistant callosal surface points and adjacent data points may be correlated, a false discovery rate (FDR) of 0.05 was employed to control for multiple spatial comparisons (Benjamini and Hochberg, 1995; Storey, 2002). Significant group differences in callosal thickness, corrected using FDR, were coded in color and mapped on the callosal surface model.

To assess the relationship between callosal area measures obtained from the partitioning scheme, and neuropsychological scores, we utilized Spearman's rank correlational analyses examining only those callosal areas corresponding to regions for which thickness effects were observed. Spearman's correlations are not influenced by outliers in small samples and the diagnostic groups did not differ by age, education or gender, so bivariate analyses were appropriate. To control for potentially inflated Type I error by examining the relationship between three neuropsychological measures and the two callosal areas showing diseaserelated changes of callosal thickness, Bonferroni correction was applied and the new threshold of significance was set at $P<0.01$.

\section{RESULTS}

\section{Subjects}

Depressed subjects and controls did not differ significantly on demographic variables (Table 1). Patients and controls differed significantly in their Mini Mental State Examination scores. When the depressed group was dichotomized by age at illness onset (Table 2), subjects with early-onset depression were significantly older than the control group. Significant age differences were also observed between the two disease groups. Mini-Mental State Examination scores differed significantly between each disease group and the controls. In addition, the late-onset group showed a significantly higher cardiovascular risk factor score than the early-onset group. There was no significant difference in total brain volume or sex distribution among all groups. The subsample did not show significant differences on CVLT and Stroop measures (CVLT trials 1-5: $F=1.70$; $P=0.20$; CVLT long delay: $\mathrm{F}=1.67 ; P=0.20$; Stroop Part I: $\mathrm{F}=0.10 ; P=0.90)$. Mini-Mental State Examination scores differed significantly between each patient group (earlyonset and late-onset depression) and controls in the subsample of study participants for which correlations of callosal area and neuropsychological variables were examined (MMSE, early-onset subgroup $=28.80( \pm 1.66)$; lateonset subgroup $=28.77( \pm 1.01)$; controls subgroup $=29.73$ $( \pm 0.59) ; P \leqslant 0.05)$.

\section{Group Differences in Callosal Thickness}

FDR-corrected statistical maps of group differences in callosal thickness are shown in Figure 2. Significant differences were observed between all patients and controls, with depressed subjects exhibiting thinner callosal regions concentrated in the anterior third and the posterior profile of the corpus callosum (corresponding to the genu and the splenium). When subjects with early-onset depression were

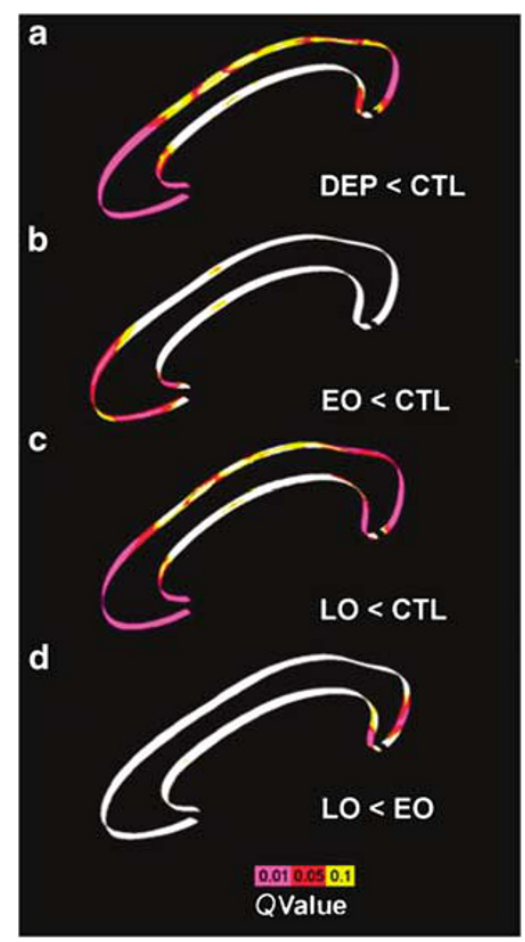

Figure 2 Corrected statistical maps (false discovery rate) showing group differences in callosal thickness between (a) all depressed patients and controls, (b) early-onset depressed patients and controls, (c) late-onset depressed patients and controls, and (d) early- and late-onset depressed patients. $\mathrm{DEP}=$ all depressed patients; $\mathrm{EO}=$ early-onset depression; $\mathrm{LO}=$ late-onset depression; $\mathrm{CTL}=$ controls. All statistical maps are corrected for age, gender and total brain volume. For all statistical maps, the color bar encodes the probability values for the observed effects.

compared with the healthy individuals, the regions in which the corpus callosum was thinner in depressed subjects became restricted to the anterior third, whereas comparison between late-onset depression and controls revealed prominent callosal thinning in the anterior third as well as the splenium. Significant group differences were also detected between the two disease groups, with reduced callosal thickness in the splenium in the late-onset depressed group compared to the early-onset depressed group.

\section{Group Differences in Callosal Area Measurements}

In traditional area analyses, patients overall had a significant reduction in the anterior third and the splenium when compared to controls (Table 1). Follow-up analyses are reported in Table 2. Early-onset depressed subjects exhibited significantly smaller areas in the anterior third compared to controls. Late-onset depressed patients showed significantly smaller areas in both the anterior third and the splenium than controls. Additionally, the area of the splenium was significantly smaller in late-onset depressed patients compared to the early-onset depressed group. None of the other comparisons resulted in statistically significant results.

\section{Neuropsychological Testing}

In the subsample for which neuropsychological measures were available, significant correlations emerged for the 
late-onset depressed patients between the CVLT Trials 1-5 and area reduction in the genu $(r=0.75, P=0.003)$ and splenium ( $r=0.61, P=0.03$ ). Late-onset depressed patients also showed associations between attention/processing performance on the Stroop Part 1 and areas of the genu $(r=-0.54, P=0.05)$ and splenium $(r=-0.74, P=0.004)$. CVLT long delay was not related to callosal areas among late-onset patients. There were no significant interactions between cognitive performance and callosal areas for earlyonset patients or controls. For late-onset patients, the significant correlations between CVLT Trials $1-5$ and the genu area and between the Stroop Part 1 and splenium area survived Bonferroni correction.

\section{DISCUSSION}

To our knowledge, this is the first study to investigate callosal abnormalities in elderly depression and relate them to age at illness onset. We applied novel computational mesh-based methods to calculate and compare callosal thickness between groups at high spatial resolution. In addition, we also used traditional morphometric methods. Four key findings emerged from our study: (1) significant reduction of callosal thickness mostly pronounced in both the genu and the splenium when the depressed cohort was combined and compared to healthy subjects; (2) significant callosal thinning confined to the genu in early-onset depression compared to controls; (3) prominent decreases of callosal thickness in the genu as well as the splenium when late-onset depressed patients and controls were compared, and (4) significant regional reduction in the area of the splenium in the late-onset depressed group relative to the early-onset depressed group. Computational mapping of highly localized reductions in callosal thickness were confirmed by more traditional area measure analyses based on the Witelson partitioning boundaries.

Previous investigations of callosal morphology in depressed populations have almost exclusively relied on younger adults, with negative results (Brambilla et al, 2004; Husain et al, 1991; Parashos et al, 1998) and positive results (Lacerda et al, 2005; Lyoo et al, 2002; Wu et al, 1993). Some studies found callosal atrophy in patients with secondary (organic) causes of depression, such as multiple sclerosis (Schilling et al, 2006) and tumors (Nasrallah and McChesney, 1981; Tanaghow et al, 1989). In the context of elderly depression, the present findings of anterior and posterior callosal abnormalities in patients $v s$ controls may be consistent with one previous study using magnetization transfer imaging, which reported significantly lower magnetization ratios in the genu and splenium of the corpus callosum (Kumar et al, 2004). On the other hand, two diffusion tensor imaging studies have not found evidence of callosal abnormalities (Bae et al, 2006; Nobuhara et al, 2006) in depressed elders. In addition, one report employing Witelson's segmentation criteria of corpus callosum areas obtained from midsagittal MRI section in a mixed elderly population did not detect an association between callosal atrophy and mood disturbances (Ryberg et al, 2007). The lack of consistency in findings may reflect methodologic differences in imaging and sample characteristics, or effects may be relatively subtle and difficult to detect in small samples.

Indirect support for our results is however provided by the considerable literature linking prefrontal abnormalities and changes in temporal lobe structures to elderly depression (for review see Alexopoulos et al, 2005). Monkey and human studies indicate that prefrontal, premotor and motor fibers cross through the anterior part of the corpus callosum, whereas temporal, parietal, and occipital fibers cross through the caudal part (de Lacoste et al, 1985; Pandya and Rosene, 1985; Pandya and Seltzer, 1986).

In view of these connectivity patterns, the present finding of callosal thinning restricted to the genu in early-onset depression relative to controls may possibly indicate abnormal connections with prefrontal areas, in line with our own previous findings of frontal gray matter abnormalities in patients with an early onset of illness (Ballmaier et al, 2004a, b).

In contrast, reduced callosal thickness in both the genu and splenium in late-onset depression compared to controls may reflect a more widespread compromise in corticocortical connectivity. Thinning of the callosal genu may also relate to decreased connectivity in prefrontal areas. Indeed, frontal lobe atrophy has been reported in late-onset depression (Almeida et al, 2002; Kumar et al, 1998). In addition, an attenuation of the 'normal' volumetric asymmetry in the frontal lobes was found in late-onset depressed subjects compared to healthy controls (Kumar et al, 2000).

Moreover, genu as well as splenium thinning may corroborate results from our previous work (Ballmaier et al, 2004c), showing widespread decreases in temporal and parietal gray matter in late-onset depression compared to controls, with prominent decreases in sensorimotor regions. Deficits were more pronounced in the right than in the left hemisphere (Ballmaier et al, 2004c), implying a possible involvement of abnormalities in inter-hemispheric information transfer in late-onset depression (Kumar et al, 2000).

Perhaps of most interest, however, is our finding of differences in callosal morphology between the two disease groups. Several distinctions between these groups have been identified, and subjects with early-onset depression are more likely to have a family history of psychiatric illness (Brodaty et al, 2001), while subjects with late-onset depression have greater subcortical ischemic disease (Krishnan et al, 1988; Salloway et al, 1996; Taylor et al, 2004). In addition, late-onset depression has been associated with more pronounced temporal lobe atrophy (Greenwald et al, 1997; Kumar et al, 1998) and hippocampal volume reductions (Steffens et al, 2000; Hickie et al, 2005), with specific genotypes possibly mediating this effect (Taylor et al, 2005). If these previous investigations are interpreted to be signs of different causes or risk factors for depression based on age at onset, greater splenium thinning in late- than early-onset depression might indeed point to more prominent atrophic or neurodegenerative processes in temporal connections, possibly reflecting higher risk for cognitive impairment and dementia conversion in the future (Geda et al, 2006; Salloway et al, 1996; Schweitzer et al, 2002; van Ojen et al, 1995). Indeed, regionally specific posterior callosal atrophy has been reported in mild 
Alzheimer's disease (Lyoo et al, 1997; Wang et al, 2006; Yamauchi et al, 2000).

Preliminary data in our subsample indicate a significant relationship between genu volumes and learning scores of the CVLT, and a significant correlation between splenium volumes and attention/motor scores of the Stroop Part 1 in late-, but not early-onset depression or controls. Since neuropsychological measures were in the normal range, these associations may reflect an early indicator of cognitive impairment becoming clinically evident only with further illness progression. On the other hand, callosal abnormalities did not correlate with scores of the CVLT long delay, mostly linked with early Alzheimer's disease (Wang et al, 2006). This might argue against the hypothesis that patients with late-onset depression are at increased risk of developing dementia. Such an interpretation, however, requires great caution, because some evidence suggests that callosal changes occur very early in the dementing process before detection with neuropsychological assessments is possible (Wang et al, 2006). In addition, interpretations are overall limited by the small size of the subsample for which neuropsychological measures were available.

Other limitations of this study should be noted. The study groups were relatively small, and although corrections for multiple comparisons were performed, negative results must be interpreted with caution. Notwithstanding, since this is, to our knowledge, the first study to identify regionspecific callosal abnormalities in elderly depression, replication with a large homogeneous group of subjects may serve to confirm our present findings. However, it should be kept in mind that midsagittal areas of the corpus callosum do not necessarily reflect abnormalities of the whole structure and true loss of connectivity. In addition, other factors, such as ischemic damage and medication effects may have confounded our results and would need to be carefully considered in future studies. Our patient and control groups were not optimally matched for gender, which is an important variable affecting callosal size (Luders et al, 2006b; Narr et al, 2002). At the same time, all our analyses included age, gender, and total brain volume as covariates, thereby reducing the risk of possible confounding effects. Further studies may be needed to investigate the specific contribution of gender to callosal abnormalities in early- and late-onset depression.

In conclusion, this study reports differentially localized patterns of callosal thinning between early- and late-onset elderly depression. In addition, a tentative association between genu and splenium thinning and learning, and attentional/motor functioning was found in late-onset depression, but not in early-onset depression or controls. Further longitudinal research will be needed to clarify callosal abnormalities in relation to altered cortical disconnections in both disease groups, and how the associations between local callosal abnormalities and neuropsychological functioning may predict later cognitive decline.

\section{ACKNOWLEDGEMENTS}

This work was supported by the National Institutes of Health through research grants (R01-MH-63674, MH-55115,
MH-61567, MH-02043) to Dr Kumar, the Career Development Award (K01 MH073990) to Dr Narr, the NIH Roadmap for Medical Research U54 RR021813 entitled Center for Computational Biology (CCB) and the NIH/NLM resource Grant P41 RR013642 to Dr Toga. Additional support was provided by the General Clinical Research Center (GCRC) awarded to the UCLA Medical Center.

\section{DISCLOSURE/CONFLICT OF INTEREST}

Dr Kumar has received financial support from the National Institutes of Health, the American Association for Geriatric Psychiatry and Bristol Meyers Squibb (one time consultant). Dr Heinz has received research funding from the German Research Foundation and the Bernstein Center for Computational Neuroscience Berlin (German Federal Ministry of Education and Research), Eli Lilly and Company, JanssenCilag, and Bristol-Myers Squibb. Dr Heinz has received Speaker Honoraria from Janssen-Cilag, Johnson and Johnson, Lilly, Pfizer and Servier.

\section{REFERENCES}

Alexopoulos GS, Schultz SK, Lebowitz BD (2005). Late-life depression: a model for medical classification. Biol Psychiatry 58: 283-289.

Alexopoulos GS, Young RC, Meyers BS, Abrams R, Shamoian CA (1988). Late-onset depression. Psychiatr Clin North Am 11: $101-115$.

Almeida OP, Burton EJ, Ferrier N, McKeith IG, O’Brien JT (2002). Depression with late onset is associated with right frontal atrophy. Psychol Med 33: 675-681.

Bae JN, MacFall JR, Krishnan KRR, Payne ME, Steffens DC, Taylor WD (2006). Dorsolateral prefrontal cortex and anterior cingulate cortex white matter alterations in late-life depression. Biol Psychiatry 60: 1356-1363.

Ballmaier M, Kumar A, Thompson PM, Narr KL, Lavretsky H, Estanol L et al (2004c). Localizing gray matter deficits in late-onset depression using cortical pattern matching methods. Am J Psychiatry 161: 2091-2098.

Ballmaier M, Sowell ER, Thompson PM, Kumar A, Narr KL, Lavretsky $\mathrm{H}$ et al (2004b). Mapping brain size and cortical gray matter changes in elderly depression. Biol Psychiatry 55: 382-389.

Ballmaier M, Toga AW, Blanton RE, Sowell ER, Lavretsky H, Peterson J et al (2004a). Anterior cingulate, gyrus rectus, and orbitofrontal abnormalities in elderly depressed patients: an MRI-based parcellation of the prefrontal cortex. Am J Psychiatry 161: 99-108.

Benjamini Y, Hochberg Y (1995). Controlling the false discovery rate: a practical and powerful approach to multiple testing. $J$ R Stat Soc, Ser B (Methodol) 57: 289-300.

Brambilla P, Nicoletti M, Sassi RB, Mallinger AG, Frank E, Keshavan MS et al (2004). Corpus callosum signal intensity in patients with bipolar and unipolar disorder. J Neurol Neurosurg Psychiatry 75: 221-225.

Brodaty H, Luscombe G, Parker G, Wilhelm K, Hickie I, Austin MP et al (2001). Early and late onset depression in old age: different ethiologies, same phenomenology. J Affect Disord 66: 225-236.

Burvill PW, Hall WD, Stampfer HG, Emmersonm JP (1989). A comparison of early-onset and late-onset depression in the elderly. B J Psychiatry 155: 673-679.

de Lacoste MC, Kirkpatrick JB, Ross ED (1985). Topography of the human corpus callosum. J Neuropathol Exp Neurol 6: 578-591. 
Delis DC, Kramer J, Kaplan E, Ober BA (1987). California Verbal Learning Test (CVLT) Manual. Psychological Corporation: San Antonio (TX).

Folstein MF, Folstein SE, McHugh PR (1975). 'Mini-mental-state': a practical method for grading the cognitive state of patients for the clinician. J Psychiatr Res 12: 189-198.

Gazzaniga MS (2000). Cerebral organization and interhemispheric communication: does the corpus callosum enable the human condition? Brain 123: 1293-1326.

Geda YE, Knopman DS, Mrazek DA, Jicha GA, Smith GE, Negash S et al (2006). Depression, apolipoprotein E genotype, and the incidence of mild cognitive impairment. Arch Gen Psychiatry 63: 435-440.

Greenwald BS, Kramer-Ginsberg E, Bogerts B, Ashtaru M, Aupperle PM, Wu H et al (1997). Qualitative magnetic resonance imaging findings in geriatric depression. Possible link between later-onset depression and Alzheimer's disease? Psychol Med 27: 421-431.

Hamilton M (1967). Development of a rating scale for primary depressive illness. Br J Soc Clin Psychol 6: 278-296.

Heun R, Kockler M, Papassotiropoulos A (2000). Distinction of early- and late-onset depression in the elderly by their lifetime symptomatology. Int $J$ Geriatr Psychiatry 15: $1138-1142$.

Hickie I, Naismith S, Ward PB, Turner K, Scott E, Mitchell P et al (2005). Reduced hippocampal volumes and memory loss in patients with early- and late-onset depression. Br J Psychiatry 186: 197-202.

Hofer S, Frahm J (2006). Topography of the human corpus callosum revisited: comprehensive fiber tractography and using diffusion tensor magnetic resonance imaging. Neuroimage 32: 989-994.

Husain MM, Figiel GS, Lurie SN, Boyko OB, Ellinwood EH, Nemeroff CB et al (1991). MRI of corpus callosum and septum pellucidum in depression. Biol Psychiatry 29: 300-301.

Krishnan KR, Goli V, Ellinwood EH, France RD, Blazer DZ, Nemeroff CB (1988). Leuokoencephalopathy in patients diagnosed as major depressive. Biol Psychiatry 23: 519-522.

Krishnan KR, Hays JC, Blazer DG (1997). MRI-defined vascular depression. Am J Psychiatry 154: 497-501.

Krishnan KR, Hays JC, Tupler LA, George LK, Blazer DG (1995). Clinical and phenomenological comparisons of late-onset and early-onset depression. Am J Psychiatry 152: 785-788.

Kumar A, Bilker W, Lavretsky H, Gottlieb G (2000). Volumetric asymmetries in late-onset mood disorders: an attenuation of frontal asymmetry with depression severity. Psychiatry Res 100: 41-47.

Kumar A, Gupta RC, Thomas MA, Alger J, Wyckoff N, Hwang S (2004). Biophysical changes in normal-appearing white matter and subcortical nuclei in late-life major depression using magnetization transfer. Psychiatry Res 130: 131-140.

Kumar A, Zin Z, Bilker W, Udupa J, Gottlieb G (1998). Late onset minor and major depression: early evidence for common neuroanatomical substrates detected by using MRI. Proc Natl Acad Sci USA 95: 7654-7658.

Lacerda ALT, Brambilla P, Sassi RB, Nicoletti MA, Mallinger AG, Frank E et al (2005). Anatomical study of corpus callosum in unipolar depression. J Psychiatry Res 39: 347-354.

Luders E, Narr KL, Zaidel E, Thompson PM, Jancke L, Toga AW (2006a). Parasagittal asymmetries of the corpus callosum. Cereb Cortex 16: 345-354.

Luders E, Narr KL, Zaidel E, Thompson PM, Toga AW (2006b). Gender effects on callosal thickness in scaled and unscaled space. Neuroreport 17: 1103-1106.

Lyoo IK, Kwon JS, Lee SJ, Han MH, Chang C, Seo CS et al (2002). Decrease in genu of the corpus callosum in medication-naïve, early-onset dysthymia and depressive personality disorder. Biol Psychiatry 52: 1134-1143.
Lyoo IK, Satlin A, Lee CK, Renshaw PF (1997). Regional atrophy of the corpus callosum in subjects with Alzheimer's disease and multi-infarct dementia. Psychiatry Res 74: 63-72.

Narr KL, Cannon TD, Woods RP, Thompson PM, Kim S, Asunction D et al (2002). Genetic contributions to altered callosal morphology in schizophrenia. J Neuroscience 22: 3720-3729.

Narr KL, Thompson PM, Sharma T, Moussai J, Khaledy M, Jang S et al (2000). Mapping morphology of the corpus callosum in schizophrenia. Cereb Cortex 10: 40-49.

Nasrallah HA, McChesney CM (1981). Psychopathology of corpus callosum tumors. Biol Psychiatry 16: 663-669.

Nobuhara K, Okugawa G, Sugimoto T, Minami T, Tamagaki C, Takase $\mathrm{K}$ et al (2006). Frontal white matter anisotropy and symptom severity of late-life depression: a magnetic resonance diffusion tensor imaging study. J Neurol Neurosurg Psychiatry 77: $120-122$

Pandya DN, Rosene DL (1985). Some observations on trajectories and topography of commissural fibers. In: Reeves AG (ed). Epilepsy and the Corpus Callosum. Plenum: New York. pp 21-39.

Pandya DN, Seltzer B (1986). The topography of commissural fibers. In: Leporé P, Ptito M, Japser HH (eds). Two HemispheresOne Brain: Functions of the Corpus Callosum. Alan R. Liss: New York. pp 47-73.

Parashos IA, Tupler LA, Blitchington T, Krishnan KR (1998). Magnetic resonance morphometry in patients with major depression. Psychiatry Res 84: 7-15.

Ryberg C, Rostrup E, Stegmann MB, Barkhof F, Scheltens P, van Straaten ECW et al (2007). Clinical significance of corpus callosum atrophy in a mixed elderly population. Neurobiol Aging 28: 955-963.

Salloway S, Malloy P, Kohn R, Gillard E, Duffy J, Dowell K (1996). MRI and neuropsychological differences in early- and late-onset depression. Neurology 46: 1567-1574.

Sanchez MM, Hearn EF, Do D (1998). Differential rearing affects corpus callosum size and cognitive function of rhesus monkeys. Brain Res 812: 38-49.

Schilling M, Brueckner-Totonji C, Arolt V, Baune BT (2006). A case of multiple sclerosis masked by depression and diabetic neuropathy. Psychosomatics 47: 361-363.

Schweitzer I, Tickwell V, O'Brien J, Ames D (2002). Is late onset depression a prodrome of dementia? Int J Geriatr Psychiatry 17: 997-1005.

Sled JG, Pike GB (1998). Standing-wave and RF penetration artifacts caused by elliptic geometry: an electrodynamic analysis of MRI. IEEE Trans Med Imaging 17: 653-662.

Steffens DC, Byrum CE, McQuoid DR, Greenberg DL, Payne ME, Blitchington TF et al (2000). Hippocampal volume in geriatric depression. Biol Psychiatry 48: 301-309.

Steffens DC, Otey EO, Aleopoulos GS, Butters MA, Cuthbert B, Ganguli $\mathrm{M}$ et al (2006). Perspectives on depression, mild cognitive impairment, and cognitive decline. Arch Gen Psychiatry 63: $130-138$.

Storey JD (2002). A direct approach to false discovery rates. $J R$ Stat Soc Ser B 64: 479-496.

Stroop JR (1935). Studies of interference in serial verbal reactions. J Exp Psychol 18: 643-661.

Tanaghow A, Lewis J, Jones GH (1989). Anterior tumour of the corpus callosum with atypical depression. $\mathrm{Br} J$ Psychiatry 155: 854-856.

Taylor WD, McQuoid DR, Krishnan KR (2004). Medical comorbidity in late-life depression. Biol Psychiatry 19: 935-943.

Taylor WD, Steffens DC, Payne ME, MacFall JR, Marchuk DA, Svenson IK et al (2005). Influence of serotonin transporter promoter region polymorphisms on hippocampal volumes in late-life depression. Arch Gen Psychiatry 62: 537-544.

van Ojen R, Hooijer C, Bezemer D, Jonker C, Lindelboom J, van Tilburg W (1995). Late-life depressive disorder in the 
community, I: the relationship between MMSE score and depression in subjects with and without psychiatric history. Br J Psychiatry 156: 311-315.

Vidal CN, Nicolson R, DeVito TJ, Hayashy KM, Geaga JA, Drost DJ et al (2006). Mapping corpus callosum deficits in autism: an index of aberrant cortical connectivity. Biol Psychiatry 60: 218-225.

Wang PJ, Saykin AJ, Flashman LA, Wishart HA, Rabin LA, Santulli $\mathrm{RB}$ et al (2006). Regionally specific atrophy of the corpus callosum in AD, MCI and cognitive complaints. Neurobiol Aging 27: 1613-1617.

Witelson SF (1989). Hand and sex differences in the isthmus and genu of the human corpus callosum. A postmortem morphological study. Brain 112: 799-835.
Woods RP, Grafton ST, Watson JD, Sicotte NL, Mazziotta JC (1998). Automated image registration: II. Intersubject validation of linear and nonlinear models. J Comput Assist Tomogr 22: 153-165.

Wu JC, Buchsbaum MS, Johnson JC, Hershey TG, Wagner EA, Teng $C$ et al (1993). Magnetic resonance imaging and positron emission tomography imaging of the corpus callosum: size, shape and metabolic rate in unipolar depression. J Affect Disord 28: 15-25.

Yamauchi H, Fukuyama H, Nagahama Y, Katsumi Y, Hayashi T, Oyanagi C (2000). Comparison of the pattern of atrophy of the corpus callosum in fronto-temporal dementia, progressive supranuclear palsy, and Alzheimer's disease. J Neurol Neurosurg Psychiatry 69: 623-629. 